Dinamika Sosial Budaya, Vol 22, No. 2, Desember 2020, pp 184-201

p-ISSN: 1410-9859\& e-ISSN: 2580-8524

http://journals.usm.ac.id/index.php/jdsb

\title{
PERANAN AUDIOVISUAL DALAM FENOMENA HALLYU SEBAGAI BUDAYA DAN GAYA HIDUP REMAJA DI JAKARTA
}

\author{
Monique Fiolitha M.T \\ Mahasiswa Program Studi Ilmu Komunikasi Strata 2 (S2) \\ Universitas Pelita Harapan, Tangerang \\ moniquefiolitha@gmail.com
}

Irwansyah

Departemen Ilmu Komunikasi Fakultas Ilmu Sosial dan Ilmu Politik Universitas Indonesia, Jakarta

dr.irwansyah.ma@gmail.com

\begin{abstract}
Korean culture spreads easily throughout the world, including Indonesia. We call this process as Hallyu or the Korean Wave. The exposure of Korean fever occurs through entertainment channels such as music, drama and movies. The emergence of Hallyu in Indonesia cannot be separated from the development of audiovisual technology. The purpose of this study is to see the use of audiovisual technology of Hallyu as a popular culture and lifestyle for teenagers in Indonesia. The study uses the Uses and Gratification theory, in which we can find out how the adolescents actively seek and use media to obtain information. Researchers use descriptive qualitative methods with desk reviews or desk research. The results of the study show that the Korean teenage fans in Jakarta is mostly influenced by the technology. Through audiovisual media, the Korean side generously feeds on their culture through K-drama and K-pop. These teenage Korean fans begin to follow the Korean culture and lifestyle. The role of parents is very important in order to provide direction and guidance to their teenagers to avoid bad effects.
\end{abstract}

Keywords: K-pop, Communication, Audio Visual, Uses and Gratification theory

\begin{abstract}
Abstrak
Kebudayaan Korea dengan mudah melebarkan sayapnya ke seluruh dunia, termasuk Indonesia. Proses penyebaran budaya Korea ini dinamakan Hallyu atau Gelombang Korea. Terpaan demam Korea terjadi melalui jalur hiburan seperti musik, drama, dan film. Sehingga, munculnya Hallyu di Indonesia tidak terlepas dari perkembangan teknologi audiovisual. Tujuan penelitian ini mau melihat pemanfaatan teknologi audiovisual dalam merebaknya Hallyu sebagai budaya populer dan gaya hidup remaja di Indonesia. Penelitian menggunakan teori Uses and Gratification, yang menjelaskan bagaimana remaja secara aktif mencari dan menggunakan media untuk mendapatkan informasi. Peneliti memakai metode kualitatif deskriptif dengan desk review atau desk research. Hasil penelitian
\end{abstract}


Dinamika Sosial Budaya, Vol 22, No. 2, Desember 2020, pp 184-201

p-ISSN: 1410-9859\& e-ISSN: 2580-8524

http://journals.usm.ac.id/index.php/jdsb

menunjukkan bahwa remaja penggemar Korea di Jakarta sangat dipengaruhi oleh teknologi. Melalui media audiovisual, pihak Korea secara gencar memberi asupan mengenai kebudayaan mereka lewat K-drama dan K-pop. Para remaja penggemar Korea ini mulai mengikuti budaya dan gaya hidup orang Korea. Peran orang tua sangat penting agar bisa memberikan arahan dan pedoman kepada anak remajanya untuk menghidari dampak buruk.

Kata Kunci: K-Pop, Determinasi Teknologi, Komunikasi, Audio Visual, Uses and Gratification theory 
Dinamika Sosial Budaya, Vol 22, No. 2, Desember 2020, pp 184-201

p-ISSN: 1410-9859\& e-ISSN: 2580-8524

http://journals.usm.ac.id/index.php/jdsb

\section{PENDAHULUAN}

Perkembangan teknologi yang semakin canggih menciptakan ketergantungan pada masyarakat. Teknologi memberikan kenyamanan dan kemudahan bagi masyarakat, terutama dalam mengakses informasi. Peranan teknologi berada dalam segala bidang, salah satunya pada dunia hiburan. Peran teknologi digital di dunia hiburan memiliki pengaruh penting dalam menyebarkan kebudayaan. Penyebaran nilai-nilai dan kebudayaan dari suatu negara ke dunia menciptakan budaya dunia atau world culture. Budaya didefinisikan sebagai bentuk spesifikasi yang dianut oleh kelompok tertentu dalam masyarakat. Sebutan bagi budaya yang diminati oleh banyak orang adalah budaya populer, budaya pop, atau budaya massa (Storey, 1998).

Hallyu atau Gelombang Korea menjadi sebuah fenomena menarik dalam dunia hiburan. Bila ditelusuri dari sejarah, sebelum tahun 1993 masyarakat Korea Selatan hidup di rezim otoritarian. Akibatnya pemerintah Korea Selatan sangat memproteksi kebudayaan mereka dan membatasi masuknya budaya-budaya luar. Tahun 1993, Presiden baru Korea Selatan, Kim Young Sam menghentikan rezim otoritarian. Pada November 1994, Kim menciptakan proyek globalisasi bernama Segyehwa. Proyek ini bertujuan untuk mempersiapkan masyarakat Korea Selatan dalam menerima pengaruh-pengaruh luar. Masyarakat Korea Selatan dituntut untuk kreatif dalam membuat karya agar mampu bersaing di pasaran (Park,
2016). Hasilnya, pada periode 1990-an, beberapa grup musik Korea berhasil masuk ke pasar Tiongkok. Drama Korea juga turut melanda ke beberapa negara, khusunya Hong Kong, China, dan Taiwan (Miller, 2002).

Pada akhir 1999, ungkapan Hallyu diciptakan oleh sebuah surat kabar Tiongkok, Beijing Youth Daily, dikarenakan peningkatan popularitas budaya pop Korea Selatan. Istilah Hallyu digunakan sebagai gambaran penyebaran budaya dan gaya hidup masyarakat Korea Selatan ke negara lain. Pada umumnya, Hallyu memancing masyarakat supaya mempelajari Bahasa dan kebudayaan Korea Selatan. Selain itu, dia juga merujuk pada produkproduk Korea Selatan seperti, kuliner, alat elektronik, musik, perawatan kulit dan make-up, fashion, serta film dan drama Korea (Yook et al., 2014).

Gelombang Korea pertama atau Hallyu 1.0 di Indonesia terjadi pada awal 2000-an. Drama Korea dianggap berhasil menarik emosi penontonnya dengan menggambarkan ekspektasi sosial negara berkembang, modernitas, dan kekuatan pasar global (Torre, 2008). Terdapat dua drama Korea yang berkontribusi pada kesuksesan fenomenal ini, yaitu 'Winter Sonata' and 'Daejangguem' (Jewel in the Palace) (Ju, 2018). Selang beberapa tahun, Hallyu 2.0 muncul dengan musik pop (K-Pop). Di saat itu, terdapat beberapa grup musik Korea yang menjadi terkenal di Indonesia, seperti BoA, Girls Generation, Super Junior, N-Sonic, The Boss, X5, dan TVXQ. Grup musik ini dianggap menyenangkan karena 
kemasan lagu, koreografi tarian, dan kemodisan penyanyinya yang nampak harmonis pada cuplikan video (Hennida, 2013). Berkat web 2.0 yang dibantu oleh jejaring sosial dan ponsel pintar, kegilaan K-Pop ini berhasil menjangkau seluruh dunia (Bok-rae, 2015).

Sejak awal 2010, Hallyu 3.0 masuk ke Indonesia. Kali ini, peredaran budaya Korea tidak lagi sebatas K-drama dan KPop, namun mencakup semua aliran budaya Korea. Tujuannya supaya memperluas budaya tradisional Korea ke seluruh dunia (Bok-rae, 2015). Terakhir, muncul Hallyu 4.0 yang berpotensi untuk membentuk K-Style. Kehidupan para artis Korea direkam dan dipublikasi melalui internet, seperti Instagram dan YouTube. Para penggemar Korea tertarik dan berusaha meniru gaya kehidupan artisnya, terutama para remaja (Bok-rae, 2015).

Dalam pendistribusiannya, Korea menggunakan media sosial dan YouTube yang memungkinkan interaksi antara produsen dan konsumen untuk mendapatkan penggemar yang setia. Internet juga membuat distribusi lebih murah dan cepat, cocok untuk komoditas "baru" yang memasuki pasar (Hennida, 2013). Menurut prof. Lee Oyoung, Hallyu adalah kasus pertama penyebaran budaya populer melalui teknologi informasi (Bok-rae, 2015). Adapun teknologi audiovisual memiliki peran aktif dalam pembentukan Hallyu di Indonesia.

Teknologi memengaruhi cara seseorang membuat, mengonsumsi, dan berbagi seni di media. Bentuk seni dapat berubah melalui penggunaan reproduksi mekanik yang memungkinkan produksi massal dan konsumsi karya seni. Benjamin (1937) mengklaim bahwa karya seni asli memiliki "aura"; ini berarti unik dalam waktu, ruang, dan keindahan (Cayari, 2011).

Audiovisual menjadi salah satu teknologi yang membangkitkan dan merangsang indra pendengaran dan penglihatan para penggemar remaja Korea. Pada teknologi audiovisual terdapat gabungan dari media digital lainnya seperti teks, gambar, suara, dan video. Gabungan ini menjadi media yang menggunakan pancaindera untuk menyampaikan pesan atau informasi ke penontonya (Dolati, 2011). Audiovisual memiliki kemampuan untuk menjangkau lebih banyak individu dalam menyebarkan pesan atau informasi (Camarero et al., 2018). Dengan demikian, fenomena Hallyu di Indonesia harus diperhatikan.

Jakarta menjadi salah satu kota yang terpengaruh oleh Hallyu. Para remaja di Jakarta telah mengadopsi gaya berdandan dan berpakaian ala Korea dalam kesehariannya. Fase remaja dipahami sebagai masa-masa permulaan pubertas dan pembentukan kemandirian sosial. Usia yang tergolong remaja adalah usia 10-18 tahun, tetapi bisa juga rentang umur 9-26 tahun, tergantung pada sumbernya (Curtis, 2015).

Jumlah fandom (penggemar Korea) di kalangan remaja juga meningkat. Kamus Oxford memberikan dua definisi dari kata fandom: 1) keadaan atau kondisi menjadi penggemar seseorang atau sesuatu, 2) penggemar orang 
Dinamika Sosial Budaya, Vol 22, No. 2, Desember 2020, pp 184-201

p-ISSN: 1410-9859\& e-ISSN: 2580-8524

http://journals.usm.ac.id/index.php/jdsb

tertentu, tim, serial fiksi, dll. Yang dianggap secara kolektif sebagai komunitas atau subkultur (Trzcinska, 2019). Segala hal tentang Korea menjadi sorotan atau fokus utama bagi sekumpulan remaja yang punya ketertarikan terhadap Hallyu, dimana budaya Korea dapat mengubah paradigma masyarakat.

Penelitian ini ingin melihat seberapa kuat peranan teknologi audiovisual dalam fenomena Hallyu merubah budaya dan gaya hidup para remaja Jakarta. Konten hiburan yang disajikan oleh Korea secara berlebihan ditakutkan bisa mempengaruhi fungsi pemikiran remaja yang rentan. Akibatnya muncul penggemar Korea yang fanatik, seperti tingkat konsumerisme yang tidak masuk akal dan rasa kepemilikan objek yang berlebihan. Dalam hal ini penggemar bukan produser atau sutradara yang mengatur kehidupan idolanya.

\section{Determinasi Teknologi}

Determinasi teknologi adalah
sebuah gagasan bahwa teknologi
memiliki efek penting pada kehidupan
kita dalam memutuskan sesuatu. Bagi
beberapa masyakarat, perkembangan
teknologi dapat membebaskan mereka
dari kesulitan; namun tidak sedikit pula
yang kehilangan sisi kemanusiaan dan
terjerat dalam jaringan teknologi yang
semakin rumit, terasing, dan berbahaya
(Adler, 2006).
Dalam teori determinasi
teknologi yang tertulis di The
Guttenberg Galaxy: The Making of

Typographic Man, Marshall MchLuhan (1962) menjelaskan bahwa teknologi membentuk pola berpikir, perilaku, dan cara hidup individu dalam bermasyarakat. Hal ini mengarahkan manusia untuk hidup sesuai dengan perubahan teknologi. Contohnya dimulai dari masyarakat suku yang belum mengenal huruf. Kemudian lanjut ke masyarakat yang mulai menggunakan peralatan komunikasi cetak. Dan yang terakhir menuju masyarakat dengan peralatan komunikasi elektronik.

Dampak dari teknologi adalah mengubah opini atau konsep dan persepsi manusia dari segi rasio dan pola kehidupan. Determinasi teknologi yang digambarkan oleh McLuhan difokuskan pada media. Pesan yang disampaikan oleh media dianggap memiliki peranannya sendiri karena bisa membentuk pergaulan dan tindakan manusia. Akan tetapi, media tidak hanya digunakan sebagai penyampai pesan, namun memiliki peranannya tersendiri. Sehingga "isi" dari pesan dan media yang digunakan sama-sama bisa mempengaruhi masyarakat (McLuhan, 1964).

McLuhan menggambarkan empat periode sejarah kehidupan manusia. Pertama, era suku atau purba (a tribal age). Pada periode ini, indera pendengaran menjadi faktor utama dalam berkomunikasi. Media pada zaman itu adalah tuturan cerita, dongeng, dan narasi dari mulut narasumber. Kedua, era literal/huruf (literate age). Pada era ini fonetik alfabet menjadi fokus utama dalam 
berkomunikasi. Sehingga indera penglihatan sudah mulai diandalkan. Ketiga, era cetak (a print age). Komunikasi pada periode ini dilakukan secara linear dan massal. Mesin cetak menjadi bagian yang penting pada era ini. Keempat, era elektronik (electronic age). Periode elektronik dianggap sebagai era yang sangat mutakhir, menggantikan massa sebelumnya. Pada era ini segalanya menjadi praktis. Di era ini ditemukan berbagai macam teknologi komunikasi, seperti telegram dan telepon (McLuhan, 1964).

Media elektronik menyatukan dunia menjadi sebuah kesatuan sistem sosial, politik, dan budaya yang besar. Hal ini disebut "global village". Sehingga, tidak ada lagi batasan di antara belahan dunia. Media massa mampu menyatukan antar manusia kapan saja, dimana saja, dan seketika itu juga (McLuhan, 1964). Tanpa disadari, perkembangan teknologi komunikasi telah mempengaruhi kebudayaan manusia dan perilaku masyarakat. Radio menjadi media pembawa informasi yang menggunakan indera pendengaran (audio). Sedangkan informasi lewat televisi dapat diperoleh dari dua pancaindera, yaitu penglihatan dan pendengaran (audiovisual) (Sartono, 2008). Informasi dari dua media ini akan masuk ke pemikiran dan mempengaruhi kehidupan masyarakat sehari-hari. McLuhan (1964) menyimpulkan bahwa media adalah pesan itu sendiri (the medium is the message).
Teknologi audiovisual menjadi fokus pada penelitian ini karena bisa memberikan informasi mengenai kebudayaan Korea Selatan yang mempengaruhi budaya dan gaya hidup remaja di Jakarta. Fase remaja masih membutuhkan stimulus yang tepat supaya bisa menunjang perkembangannya di era teknologi. Penggunaan teknologi pada remaja yang salah bisa berakibat fatal. Hal ini bisa berpotensi pada pembentukan karakter remaja di Jakarta.

\section{Teori Uses and Gratification}

Teori yang digagas oleh Blumler, Gurevitch, dan Katz ini beranggapan bahwa pengguna media dapat berperan aktif dalam memilih media. Seseorang menggunakan teknologi agar memenuhi kebutuhan dan tindakan mereka (Griffin et al., 2019). Teori ini berfokus kepada individu yang menggunakan media ketimbang pesan dari medianya (Littlejohn et al., 2017). Terdapat lima asumsi dasar dari uses and gratification. Pertama, pengguna media itu aktif. Individu yang menggunakan media bukanlah pihak yang pasif, namun berperan dalam menggunakan dan memilih isi program. Kedua, pengguna media bebas menyeleksi media dan memilih program apa yang memuaskan kebutuhannya. Ketiga, media saling bersaing untuk memperoleh perhatian dan waktu masyarakat. Keempat, media memberikan efek secara berbeda kepada setiap penggunanya. Kelima, pengguna media perlu mempertimbangkan nilai-nilai yang 
ditampilkan oleh media (Griffin et al., 2019).

Terdapat beberapa alasan yang menyebabkan masyarakat menggunakan media, yaitu motif untuk mendapatkan informasi, kebutuhan untuk menunjukkan identitas pribadi dalam kehidupan sosial, motivasi menggunakan media supaya hubungan antarindividu langgeng, dan kebutuhan akan hiburan (Miller, 2002)

Disaat industri teknologi
informasi memberikan beragam
platform dengan konten yang berbeda-
beda, uses and gratification dapat
digunakan untuk memberi motif,
manfaat, serta kebutuhan remaja
terhadap penggunaan teknologi. Tujuan
teori uses and gratification untuk
menjelaskan alasan penggemar Korea di
kalangan remaja mencari konten
tentang K-drama, K-pop, dan K-style
secara aktif, khususnya artis idola
mereka. Pertanyaan ini dapat dijawab
dalam tiga aspek teori uses and
gratification. Pertama, menjelaskan
alasan fandom Korean di kalangan
remaja menggunakan teknologi
audiovisual sebagai pemuas kebutuhan.
Kedua, menunjukkan motif dasar
fandom Korea di kalangan remaja dalam
menggunakan teknologi audiovisual.
Ketiga, memahami dampak positif dan
negatif dari penggunaan teknologi
audiovisual bagi fandom Korea di
kalangan remaja.

\section{Metodologi Penelitian}

Penelitian ini ingin mengetahui pengembangan teknologi audiovisual kepada para fandom Korea di kalangan remaja di Jakarta. Metode yang digunakan dalam penelitian ini adalah pendekatan kualitatif deskriptif dengan desk review atau desk research. Metode kualitatif deskriptif dipilih karena ingin menggambarkan, menjelaskan, dan membentuk hubungan dari kategori data yang ada (Moleoeng, 2000). Desk review adalah tindakan mengumpulkan data pendukung dari informasiinformasi yang sudah ada. Informasi data ini digabungkan agar bisa menarik suatu kesimpulan (Creswell \& Creswell, 2018).

\section{Pembahasan}

\section{Teknologi}

Secara budaya, moral, dan politik, teknologi adalah alat yang bisa digunakan untuk mendukung gaya kehidupan. Teknologi bersifat netral bila dilihat dari sisi dasar konstruksi sebuah mesin dan prinsip kerjanya; namun dianggap tidak netral bila menyangkut aktivitas manusia di sekitar mesin, yang meliputi kegunaan praktis, status simbol, dan keterampilan pemilik (Pacey, 2000).

Terdapat tiga aspek penerapan teknologi menurut Pacey (2000), yaitu aspek organisasi (organizational aspect), aspek budaya (cultural aspect), dan aspek teknis (technical aspect).

1. Aspek Organisasi (Organizational Aspect)

Aspek ini mencakup sisi administrasi dan kebijakan publik. Hal ini berhubungan dengan aktivitas dari 
desainer, insinyur, teknisi, dan produksi pekerja, serta mencakup penjual dan konsumen dari sisi ekonomi.

2. Aspek Teknis (Technical Aspect) Mencakup sisi pengetahuan, mesin, teknik, kemampuan, serta hal lain yang mendukung perkembangan teknologi.

3. Aspek Budaya (Cultural Aspect)

Dalam perkembangannya, teknologi berhubungan dengan nilai-nilai dan kode etik, ide, kesadaran, dan aktivitas kreatif.

Pada aspek teknis, teknologi kadang kala bisa mengalami kerusakan. Di aspek organisasi, teknologi kadang membutuhkan perawatan. Kemudian, dari sisi budaya, teknologi dirancang sesuai dengan budaya pencipta teknologi tersebut. Ketiga aspek tersebut dikelompokkan lagi oleh Pacey (2000) ke dalam dua ranah. Pertama, ranah pengguna (user sphere) yang mencakup aspek budaya dan aspek organisasi. Kedua, ranah asli (expert sphere) yang di dalamnya ada aspek teknis.

\section{Macam-macam Media Audiovisual}

Proses penyebaran Hallyu dibantu oleh peranan media audiovisual. Mediamedia tersebut membantu pembentukan fandom Korea di kalangan remaja Jakarta. Informasi berupa audio (suara), visual (gambar), dan karakteristik media audiovisual lainnya merangsang indera pendengaran dan penglihatan mereka. Berikut tiga keuntungan dari media audiovisual (Camarero et al., 2018), yaitu:

1. Demokrasi Komunikatif

Siapa pun dapat membuat video dan menyebarkannya dengan tujuan menciptakan dampak yang lebih besar atau kecil pada pengguna.

2. Jangkauan dan potensi difusi

Pesan dalam video lebih dapat memberikan kesan yang kuat dan citra kredibilitas di antara khalayak.

3. Ekonomi produksi

Keuntungan dari video online adalah tidak membutuhkan investasi besar. Hampir semua perangkat seluler bisa merekam, mengedit, dan menyebarkan konten audiovisual. Sosial jaringan seperti Youtube, Video, dan Facebook bisa melakukan siaran langsung.

Media audiovisual membantu memudahkan dalam proses penyampaian dan dapat menyajikan setiap informasi kepada penerima pesan. Hal ini meningkatkan minat para penggemar Korea di Indonesia. Proses Hallyu dengan mudah terjadi. Format audiovisual semakin digunakan dalam proses komunikasi dan informasi. Format ini menjadi alat pengembangan pribadi dan perubahan sosial yang positif. Pengunaan media audiovisual dalam hubungan sosial menawarkan sejumlah keuntungan. Media tersebut memiliki kemampuan untuk menjangkau lebih banyak 
Dinamika Sosial Budaya, Vol 22, No. 2, Desember 2020, pp 184-201

p-ISSN: 1410-9859\& e-ISSN: 2580-8524

http://journals.usm.ac.id/index.php/jdsb

individu serta menyebarkan pesan atau informasi (Camarero et al., 2018). K-drama dan K-pop, berhasil menjangkau audiens secara global dengan bantuan media audiovisual.

Menurut Rudi Bertz, dikutip dari Ester Magdalena Kembuan (2019) mengatakan bahwa tingkat keefektivan media audiovisual lebih tinggi. Hal ini dikarenakan audiovisual mempunyai ciri-ciri utama dari media. Bentuk visual dibentuk ke dalam tiga pokok. Pertama, gambar visual. Kedua, garis (linier graphic). Ketiga adalah simbol. Dengan demikian, audiovisual punya keefektifan yang tinggi. Berdasarkan riset Rudi Bertz, rata-rata media audiovisual memiliki keefektifan diatas 60\% hingga $80 \%$ (Kembuan \& Irwansyah, 2019).

Industri hiburan Korea Selatan berusaha mengemas drama, film, dan musik semenarik mungkin hingga diminati oleh masyarakat negara lain. Terdapat dua dominan yang mencerminkan budaya populer Korea, yaitu drama televisi (Kdrama) dan musik (K-pop) (Yook et al., 2014).

\section{Peranan Media Audiovisual YouTube Terhadap Perkembangan Hallyu K-pop}

Youtube adalah situs web kedua yang paling sering dikunjungi di seluruh dunia. Beberapa video bisa berada di puncak perhatian setelah dipublikasi, namun ada juga video yang tidak menerima perhatian sama sekali. YouTube menjadi website paling umum untuk mengakses video (Bärtl, 2018).
Terdapat dua tipe Youtuber. Pertama, Youtuber individu yang berusaha sendiri membuat konten portofolio YouTube yang layak ditonton. Kedua, Youtuber yang berada di dalam bisnis Marker yang memiliki skala penonton yang lebih besar (Sørensen, 2016). Bagi sebagian orang, YouTube dipandang sebagai situs web yang penuh dengan amatir yang membuang-buang waktu mereka untuk memposting video yang dibuat dengan buruk. Sementara yang lain melihat YouTube sebagai kesempatan mereka untuk menjadi bintang, guru paling pengertian, atau tempat pertemuan mereka dengan teman-teman terdekat. YouTube memang memungkinkan semua hal ini terjadi. YouTube berfungsi sebagai kedai kopi virtual, tempat dimana orang dapat berbagi ide dan berkumpul dengan individu yang berpikiran sama maupun berbeda untuk mendiskusikan ide, seni, dan musik (Cayari, 2011).

Perkembangan K-pop di YouTube berhasil mempromosikan musisi Korea Selatan. Peredaran Kpop terbukti bagus dilihat dari video musik mereka yang sering kali menjadi video yang paling banyak ditonton di YouTube (Shim, 2013). Dikutip dari detikINET dari Engadget, grup musik BTS dengan video musik barunya, Dynamite, berhasil memperoleh 101,1 juta penonton dalam waktu 24 jam di YouTube. Rekor ini berhasil mengalahkan Blackpink dengan lagu 'How You Like That', Taylor Swift dengan lagu 'ME!' hingga Ariana Grande dengan 'Thank You, Next". Saat ini, musik tidak 
dapat dipisahkan dengan ranah visual, dan K-Pop tidak hanya sebagai musik tetapi juga koreografi, video musik, dan lainnya. Setiap grup K-pop memiliki konsep utama mereka, seperti menjadi imut, lucu atau seksi. Hal ini guna mengikat penggemar sesuai sasaran utama mereka (Trzcinska, 2019).

Peranan teknologi audiovisual dalam meningkatkan jumlah penggemar Korea dari sisi Kpop juga terlihat ketika BTS memenangkan 'The 2017 Billboard Music Awards Top Social Artist' pada tanggal 21 Mei 2017. BTS berhasil mengalahkan artis Amerika terkenal, Justin Bieber yang telah mendominasi kategori penghargaan tersebut selama enam tahun berturut-turut. Pencapaian ini diperoleh dari partisipasi aktif mereka bersama penggemar melalui platform media sosial, salah satunya YouTube. BTS menjadi artis Asian pertama yang berhasil memenangkan kategori Artis Sosial Teratas Billboard Music Awards dan kemenangan tersebut telah menempatkan industri musik Korea dalam sorotan. Artis yang menerima penghargaan ini telah menetapkan bahwa mereka memiliki interaksi sosial yang hidup dengan penggemar karena penghargaan ini hanya berdasarkan sistem voting penggemar. BTS mendapatkan jumlah vote sebesar 300.000.000. Hasil ini jauh melampaui artis lain, seperti Justin Bieber, Selena Gomez, dan Ariana Grande (www.billboardmusicawards.com).
Kemunculan BTS yang sering tampil di V-live (aplikasi siaran online Korea), Twitter, dan YouTube telah membantu membentuk rangkaian komunikasi yang konstan dengan penggemar mereka. Salah satu taktik pihak manajemen BTS, Big Hit Entertainment dalam memuaskan fandom Korea adalah dengan memberikan teks terjemahan di setiap video musik atau video kehidupan yang dilakukan oleh BTS. Ide tersebut membuat BTS dapat menggapai dunia international, termasuk penggemar di Jakarta (Aisyah, 2017).

Selain Big Hit Entertainment, manajemen K-pop lainnya juga menggunakan pola yang sama. Bahasa Inggris menjadi keterampilan tambahan yang harus dimiliki, mengingat tidak semua penggemarnya bisa berbahasa Korea. Mereka menempatkan beberapa kata dalam Bahasa Inggris ke dalam lagu. Selain itu juga mengajarkan kepada calon-calon artis K-pop lainnya untuk belajar Bahasa Inggris (Trzcinska, 2019). Namun untuk memudahkan proses pemahaman Bahasa, pihak Korea selalu memberikan teks Bahasa Inggris di setiap videonya. Perpaduan antara visual, narasi, dan teks yang harmonis membuat penonton dibawa ke situasi yang sebenarnya (Sartono, 2008).

YouTube adalah situs yang memungkinkan banyak orang tidak hanya mengonsumsi, tetapi juga berkreasi. Pengguna YouTube dapat 
Dinamika Sosial Budaya, Vol 22, No. 2, Desember 2020, pp 184-201

p-ISSN: 1410-9859\& e-ISSN: 2580-8524

http://journals.usm.ac.id/index.php/jdsb

memasukkan video mereka ke

dalam kategori apa pun yang

mereka pilih (Cayari, 2011). Melalui

media YouTube, Hallyu terus bertindak sebagai platform yang tidak disengaja untuk konvergensi sosial dan kosmopolitanisme multibudaya. Salah satu bentuk Hallyu yang disebarkan melalui YouTube adalah dance cover. Manajemen Korea tidak hanya mengeluarkan video musik artisnya, namun juga latihan dance cover yang dapat ditiru oleh penggemarnya. Baik video musik maupun video latihan dance cover menjadi kunci untuk mempromosikan budaya tari K-pop. Para penggemar dance cover K-pop dengan senang berusaha untuk meniru dan menyempurnakan tarian grup mereka sesuai para idolanya. Dance cover ini mendapat sambutan yang baik oleh para artis K-pop (Khiun, 2013). Para fandom pecinta Korea di Jakarta juga banyak melakukan dance cover dan mempublikasikannya. Di YouTube, siapapun dengan kamera web atau smartphone dapat membuat saluran dan menyiarkan konten dengan biaya minim (Sørensen, 2016). Teknologi digital memang telah mengubah cara musisi mendistribusikan musiknya (Cayari, 2011).

\section{Peranan Media Audiovisual Televisi Terhadap Perkembangan Hallyu K- drama}

Media televisi menyiarkan pesan dengan perpaduan antara visual, narasi, dan teks secara harmonis. Hal ini membuat penonton dibawa ke situasi yang sebenarnya. Penonton melihat dan mendengar informasi dengan mata dan telinganya. Sehingga penonton tidak perlu berimajinasi terlalu dalam. Karya animasi komputer yang berkembang juga mempengaruhi kenikmatan dalam menonton (Sartono, 2008).

Televisi adalah produk lawas teknologi audiovisual yang seiring waktu mengalami perubahan pada isi siaran dan perangkatnya. Konten pada televisi ditentukan dari modal sosial, budaya, dan dinamika kekuasaan (Michalis \& Smith, 2016).

Teknologi seluler dan internet yang membuat kemudahan menonton konten di mana saja dan kapan saja merubah pola perilaku menonton tradisional. Industri TV saat ini harus mampu bersaing dan hidup berdampingan dengan sejumlah perusahaan multinasional dan produser individu untuk mengejar dan memproduksi beragam program (Sørensen, 2016).

Logika distribusi televisi harus berubah ketika layanan streaming video berkembang. Perkembangan layanan streaming 
Dinamika Sosial Budaya, Vol 22, No. 2, Desember 2020, pp 184-201

p-ISSN: 1410-9859\& e-ISSN: 2580-8524

http://journals.usm.ac.id/index.php/jdsb

video dengan konsep subscription

video on demand (SVOD)

menciptakan alternatif dalam

menonton. SVOD memberikan

ragam acara yang menarik kepada

pelanggannya. Contohnya platform Netflix, Hulu, atau Ilix. (Lobato, 2017).

Televisi dan Internet telah menjadi contoh kasus sinergi yang sangat sukses dalam konvergensi media, karena kedua media tersebut mengaktifkan penonton untuk menciptakan budaya televisi yang lebih partisipatif. Maraknya layanan streaming online, seperti Netflix, mengelolah paket program videoon-demand dan streaming TV dalam lingkup global (Ju, 2019).

K-drama telah bergabung ke berbagai situs streaming, seperti Netflix, Hulu.com, Dramafever.com, dan Viki.com, serta layanan TV satelit seperti DirecTV (Ju, 2018). Tingkat keminatan masyarakat dalam menonton acara TV asing meningkat pesat karena difasilitasi oleh teknologi streaming web. Selain itu, media audiovisual juga berdampak pada pembentukan budaya penggemar online dalam menonton acara TV transnasional, termasuk di Jakarta.

Tercatat bahwa popularitas transnasional K-drama telah membentuk sentralitas baik komedi romantis maupun melodrama, dan katalog K-drama Netflix sangat cocok dengan tren ini. Para remaja di Jakarta menikmati kebudayaan yang ditampilkan dalam K-drama dengan mengidentifikasi cara hidup, nilai, penampilan fisik, dan hubungan cinta masyarakat Korea. K-drama suka menampilkan kebudayaan, cara berpakaian, kuliner, dan tempat wisata masyarakat Korea. Kebudayaan ini secara tidak langsung mempengaruhi kehidupan para penonton, khususnya para remaja. (Ju, 2019). Salah satu k-drama yang menampilkan itu semua adalah 'Itaewon Class'. K-drama yang baru liris tahun 2020 ini, menampilkan masakan-masakan traditional masyarakat Korea yang nampak lezat. Bukan hanya itu saja, K-drama ini juga menampilkan tempat wisata dan cara hidup para remaja di Korea, bagaimana cara mereka menikmati kehidupan malam dan budaya minum orang Korea. K-drama lainnya yang mempengaruhi gaya hidup remaja Indonesia adalah drama TV 'You Who Came From The Stars'. Akibat drama ini tren makan ayam goreng dengan bir (chi-maek) menyebar. Dampaknya restoran waralaba Korea seperti 'BibiGo' dan 'School Foods' dibuka di kota-kota besar seperti Jakarta (Jeong et al., 2017).

Di sektor perfilman, Hallyu mempengaruhi penetrasi drama Korea di Indonesia. Kasus ini dapat dilihat dari munculnya produksi sinetron Indonesia yang mengadopsi cerita K-drama. Pada tahun 2010, tercatat ada 51 sinetron TV yang menampilkan unsur-unsur mirip dengan K-drama. Produksi drama 
Korea yang mirip menunjukkan bahwa produser drama TV lokal bereaksi terhadap popularitas Kdrama yang tinggi untuk keuntungan bisnis mereka. Beberapa K-drama terkenal yang menjadi inspirasi sinetron lokal adalah 'My Girl', 'Starway to Heaven', 'Endless Love', 'My Name is Kim Sam Soon' dan 'Boys Over Flowers'. Terdapat banyak sinetron TV lokal yang memiliki alur cerita, dialog, soundtrack musik, dan adegan yang mirip dengan drama Korea. Pengaruh K-drama di sektor sinetron Indonesia bergerak melampaui kuantitas (Anwar, 2019).

Berdasarkan responden dari penelitian Ratih Pratiwi Anwar (2019), K-drama memberikan pengaruh yang baik bagi sinetron TV Indonesia. Kualitas drama TV lokal meningkat. Tayangan episode sinetron TV lokal menjadi lebih pendek seperti K-drama (Anwar, 2019).

Remaja Jakarta sebagai generasi digital dan gaya hidup mereka yang berubah

Teori Uses and Gratifications menyatakan bahwa masyarakat adalah khalayak aktif dalam mengonsumsi media dan konten media. Masyarakat aktif karena mereka mencari gratifikasi tertentu melalui konten media (Griffin et al., 2019).

Remaja penggemar Korea di Jakarta adalah khalayak media yang secara aktif mencari konten Hallyu di media untuk mereka konsumsi dan untuk memenuhi kepuasannya. Mereka menggunakan media untuk menemukan kegembiraan dari serial drama televisi, film, atau pertunjukan musik Korea. Kegiatan ini dilakukan guna melarikan diri dari tugas sehari-hari, atau untuk melakukan interaksi sosial (Putri \& Reese, 2016).

Diasumsikan bahwa remaja penggemar Korea di Jakarta mungkin merasa mengenal artis favoritnya dengan baik (interaksi parasosial) dan hal ini memotivasi mereka untuk mengikuti aktivitas idolanya dengan berbagai cara. Mereka termotivasi dan melibatkan khalayak media, mengarahkan mereka untuk belajar, mencontoh, dan membentuk sikap yang setara dengan konten media Korea yang mereka konsumsi (Putri \& Reese, 2016).

Bora (2015) secara khusus membahas tentang dampak media massa terhadap difusi budaya. Media menyebarkan unsur budaya antara lain kuliner, kebiasaan, pakaian, kepercayaan agama, tari, bahasa, dan banyak lagi lainnya (Putri \& Reese, 2016). Teknologi digital telah menjadi bagian penting dari pengalaman kontemporer, khususnya bagi kaum remaja. Bentuk media yang baru telah melahirkan budaya digital yang tidak hanya mencakup produksi dan konsumsi konten digital secara luas, tetapi juga perubahan sikap dan gaya hidup (Hwang, 2004). Gaya 
hidup baru generasi digital remaja Jakarta mempercepat transformasi distribusi budaya, terutama bila pengguna mengonsumsi dan mendistribusikan produk K-pop (Anwar, 2019).

Fenomena Hallyu di Indonesia, khususnya Jakarta tidak hanya ditemukan pada produk budaya media, seperti drama TV (Kdrama) dan video musik (K-pop) saja. Tetapi Hallyu juga terdapat pada pola gaya hidup yang lebih luas, seperti makanan, kosmetik, dan pariwisata (Jeong et al., 2017).

Remaja Jakarta suka meniru kebudayaan dan gaya hidup idola Korea mereka. Mereka mengadopsi gaya busana dan pola kehidupan orang Korea yang suka mampir ke kedai kopi untuk berkumpul bersama teman. Selain itu, mereka juga membeli dan menggunakan produk-produk bermerek Korea, serta membeli banyak hal berkaitan dengan Hallyu. Sebut saja album CD atau DVD, light stick fandom idola mereka, souvenir, tas, kosmetik, hingga pergi ke konser K-Pop yang mengharuskan mereka mengeluarkan banyak uang (Anwar, 2019).

Sesuatu yang sudah ada dalam diri seseorang dapat diubah oleh media. Baik dari aspek pengetahuan, keyakinan, standar, hingga suasana hati seseorang. Konten media Korea mengubah standar para remaja penggemar Korea di Jakarta, seperti mengubah standar mereka dari gaya hidup
Indonesia menjadi gaya hidup Korea. Tidak hanya standar yang diubah, tetapi juga pengetahuan, keyakinan, dan suasana hati. Sambil mengonsumsi konten media Korea, para remaja ini mendapatkan semakin banyak fakta tambahan tentang Korea Selatan setiap saat. Selain itu, keyakinan mereka dapat berubah ketika media yang mereka gunakan mengungkapkan fakta yang bertentangan dengan keyakinan mereka. Menonton aksi para idola Korea juga membuat perubahan suasana hati para penggemarnya. Media juga memperkuat keyakinan dan sikap sehingga sulit diubah, terutama para remaja yang pola pikirnya masih rentan (Putri \& Reese, 2016).

\section{Peranan Orang Tua Kepada Remaja Penggemar Korea Dalam Teknologi}

Orang tua adalah panutan bagi anak-anak, termasuk di usia remaja yang pola pemikirannya masih bisa digoyahkan. Didikan setiap orang tua berbeda-beda. Pola asuh yang baik membantu menumbuhkan empati, kejujuran, kemandirian, pengendalian diri, kebaikan, dan kerja sama. Hal ini dapat memacu keingintahuan intelektual, motivasi, dan keinginan untuk mencapai tujuan seorang remaja (Patrikakou, 2016).

Pola didikan dari orang tua di rumah merupakan hal yang penting. Di tengah perkembangan teknologi ini, orang tua harus lebih rajin dalam 
mengamati prinsip-prinsip, pola hidup dan pikir anaknya. Peran dan nasihat orang tua dibutuhkan agar anak tidak menyalahgunakan teknologi. Pengawasan menjadi bagian penting dalam menghadapi kasus ini. Penggunaan teknologi oleh remaja tanpa kontrol dapat mendampak negatif (Patrikakou, 2016).

Permasalahannya orang tua tidak dapat hadir setiap saat untuk anak-anak mereka ketika menggunakan teknologi dan media. Sehingga cara alternatif yang bisa dilakukan oleh orang tua adalah menumbuhkan akuntabilitas dan kemandirian anak. Hal ini guna membuat para anak bisa mengambil rasa kepemilikan atas tindakan mereka (Patrikakou, 2016).

Teknologi dan media membuat orang tua harus terlibat dalam kehidupan anak-anaknya agar bisa berpengetahuan luas namun tetap terkendali. Patrikakou (2016) mencoba untuk memberikan solusi untuk permasalahan ini. Pertama, orang tua harus memberikan contoh bagaimana menggunakan teknologi dan media dengan baik. Berhentilah berada di depan layar sepanjang waktu. Ketika menonton K-drama, tidak perlu semua episode langsung dikelarkan dalam satu hari. Kedua, terlibatlah dalam kehidupan jejaring sosial dan teknologi anak. Ketahui bagaimana mereka menghabiskan waktu mereka secara online. Minta mereka untuk menunjukkan situs favorit mereka, video musik, dll.
Ketiga, tetapkan aturan yang jelas dan batasan untuk akses web, pengunduhan, dan waktu pemakaian. Keempat, orang tua harus menjelaskan mengenai aturan dan keputusan yang diberikan. Kelima, bila peraturan dilanggar orang tua harus menjelaskan ulang secara bijaksana. Keenam, orang tua memberikan pujian kepada anaknya yang menggunakan teknologi dan media secara positif. Ketujuh, orang tua menyesuaikan pola asuh anak ketika teknologi dan media tersebut mengalami perkembangan. Kedelapan, orang tua harus memperlakukan anaknya dengan hormat, baik di dunia maya maupun nyata (Patrikakou, 2016).

Faktor lingkungan sekitar sangat mempengaruhi seorang anak remaja dalam bertindak, termasuk kebiasaan mengakses media audiovisual dan teknologi. Keluarga adalah lingkungan terdekat anak. Oleh sebab itu, orang tua diharapkan dapat memberikan pedoman yang baik bagi sang anak, baik yang masih kecil maupun sudah di fase remaja, agar lebih bijak dalam menggunakan media dan teknologi. Karena penggunaan media audiovisual yang tidak bisa dikontrol dapat memberikan dampak negatif. Diharapkan agar anak tidak menjadi penggemar Korea yang terlalu fanatik dan bisa bertindak sewajarnya.

\section{Kesimpulan}


Dinamika Sosial Budaya, Vol 22, No. 2, Desember 2020, pp 184-201

p-ISSN: 1410-9859\& e-ISSN: 2580-8524

http://journals.usm.ac.id/index.php/jdsb

Perkembangan teknologi digital berfungsi untuk memfasilitasi kehidupan umat manusia dalam aktifitas sehari-hari. Teknologi digital membantu proses penyebaran informasi dan meningkatkan eksistensi penggunanya. Selain itu, teknologi digital juga memungkinkan proses perubahan budaya dan pola hidup masyarakat. Hallyu atau Gelombang Korea sangat ditentukan oleh media audiovisual. Pihak Korea melakukan proses penyebaran budaya melalui K-drama dan K-pop. Para penggemar Korea yang masih remaja dengan mudah mengakses drama, film, dan musik Korea lewat media audiovisual, terutama YouTube dan Televisi. K-drama dan K-pop dikemas sedemikian rupa sehingga membuat banyak orang tertarik.

Di setiap K-drama dan K-pop, pihak Korea selalu menampilkan kebudayaan dan gaya hidup masyarakatnya, seperti cara berpakaian, kuliner, kehidupan malam, dan tempat wisata. Melalui bantuan teknologi audiovisual, remaja penggemar Korea dengan mudah mengakses informasi mengenai idola Korea mereka. Remaja yang masih memiliki pemikiran yang rentan dan mudah terpengaruh menjadi sasaran empuk dari pihak Korea. Oleh sebab itu, kini banyak remaja yang bergabung dengan komunitas-komunitas pecinta Korea. Rasa cinta terhadap kebudayaan dan pola hidup masyarakat Korea juga menjadi lebih besar ketimbang nasionalisme para remaja Jakarta ini.

Oleh sebab itu, bimbingan dari orang tua terhadap penggunaan teknologi pada remaja adalah faktor yang penting. Keluarga menjadi lingkungan terdekat anaknya. Dengan memberikan contoh dan didikan yang baik, penggunaan teknologi tidak akan memberikan efek negatif kepada para remaja penyuka Korea ini. Orang tua harus bisa mengatur pola menonton dan mengakses media audiovisual anak. Selain itu, penting bagi orang tua untuk mengajarkan anaknya rasa cinta kepada tanah air dan budayanya.

\section{DAFTAR PUSTAKA [REFERENCES]}

Adler, P. S. (2006). Technological determinism. International Encyclopedia of Organization Studies. https://doi.org/10.4324/97803673517 55-2

Aisyah, A. (2017). Korean-english language translational action of k-pop social media content: a case study on bangtan sonyeondan's (bts) official twitter. The Southeast Asian Journal of English Language Studies. https://doi.org/10.17576/3L-20172303-05

Anwar, R. P. (2019). The effect of korean wave on young generation and creative industry in indonesia. October.

Bärtl, M. (2018). Youtube channels, uploads and views: a statistical analysis of the past 10 years. The International Journal of Research, 24(1), 16-32. 
Dinamika Sosial Budaya, Vol 22, No. 2, Desember 2020, pp 184-201

p-ISSN: 1410-9859\& e-ISSN: 2580-8524

http://journals.usm.ac.id/index.php/jdsb

https://doi.org/10.1177/13548565177 36979

Bok-rae, K. (2015). Past, present and future of hallyu (korean wave). American International Journal of Contemporary Research, 5(5).

Camarero, E., Fedorov, A., \& Levitskaya, A. (2018). Audiovisual and media literacy for social change.

Cayari, C. (2011). The youtube effect: how youtube has provided new ways to consume, create, and share music. International Journal of Education \& the Arts.

Creswell, J. W., \& Creswell, J. D. (2018). Research design: qualitative, quantitative, and mixed methods approaches. In SAGE Publishing (Fifth edit). https://doi.org/10.1017/СВ097811074 15324.004

Curtis, A. C. (2015). Defining adolescence. Journal of Adolescent and Family Health, 7(2).

Dolati, R. (2011). Harnessing the use of visual learning aids in the english language classroom. Arab World English Journal.

Griffin, E., Ledbetter, A., \& Sparks, G. (2019). A first look at communication theory (tenth edit). McGraw-Hill Education.

Hennida, C. (2013). Corporate strategies in the spread of hallyu (korean wave) in indonesia. Mozaik, 13(2), 117-125.

Hwang, S.-M. (2004). Cyber new generation in korea. Seoul: 21 Century Books.

Jeong, J., Lee, S., \& Lee, S. (2017). When

indonesians routinely consume korean pop culture: revisiting jakartan fans of the korean drama dae jang geum. International Journal of Communication, 11.

Ju, H. (2018). The korean wave and korean dramas. Oxford Research Encyclopedia of Communication. https://doi.org/10.1093/acrefore/9780 190228613.013.715

Ju, H. (2019). Korean tv drama viewership on netflix: transcultural affection, romance, and identities. Journal of International and Intercultural Communication, April. https://doi.org/10.1080/17513057.201 9.1606269

Kembuan, E. M., \& Irwansyah. (2019). Peran teknologi audio-visual dalam pengembangan pembelajaran anak di sekolah dasar karya anak bangsa di manado (the role of technology and audio-visual media in learning development at anak bangsa elementary school, manado). Polyglot, 15(1), 73-92.

Khiun, L. K. (2013). K-pop dance trackers and cover dancers: global cosmopolitanization and local spatialization.

Littlejohn, S. W., Foss, K. A., \& Oetzel, J. G. (2017). Theories of human communication (Eleventh E). Waveland Press, Inc.

Lobato, R. (2017). Rethinking international tv flows research in the age of netflix. Television \& New Media. https://doi.org/10.1177/15274764177 08245

McLuhan, M. (1964a). Understanding media 
Dinamika Sosial Budaya, Vol 22, No. 2, Desember 2020, pp 184-201

p-ISSN: $1410-9859 \&$ e-ISSN: $2580-8524$

http://journals.usm.ac.id/index.php/jdsb

the extensions of man London and New York. Basieexpsispittedu, 318. https://doi.org/10.2307/2711172

McLuhan, M. (1964b). Understanding media the extensions of man London and New York. Basieexpsispittedu. https://doi.org/10.1109/tpc.1987.6449 115

Michalis, M., \& Smith, P. (2016). The relation between content providers and distributors: lessons from the regulation of television distribution in the united kingdom. Telematics and Informatics.

Miller, K. (2002). Communication theories: perspective, process, and context. Boston: McGraw Hill, 244.

Pacey, A. (2000). The culture of technology. The MIT Press Edition, 1983, Ninth prin.

Park, M. (2016). South korea cultural history between 1960s and 2012. International Journal of Korean Humanities and Social Sciences. https://doi.org/10.14746/kr.2015.01.0 5

Patrikakou, E. N. (2016). Parent involvement, technology, and media: now what? School Community Journal, 26(2).

Putri, V. K., \& Reese, M. (2016). The impact of "korean wave" on young indonesian females and indonesian culture in jabodetabek area. Business and Management Studies Journal, 3(2).

Sartono, S. (2008). Teknik penyiaran dan produksi program radio, televisi, dan film.

Shim, D. (2013). Social distribution: k-pop fan practices in indonesia and the 